\title{
PCR-assisted impedimetric biosensor for colibactin-encoding pks genomic island detection in $E$. coli samples
}

\author{
Nadja E. Solis-Marcano ${ }^{1}$ • Myreisa Morales-Cruz ${ }^{1}$ - Gabriela Vega-Hernández ${ }^{1}$ • Ramón Gómez-Moreno ${ }^{2}$. \\ Claudia Binder $^{3} \cdot$ Abel Baerga-Ortiz $^{2} \cdot$ Craig Priest $^{3} \cdot$ Carlos R. Cabrera $^{1}$
}

Received: 18 March 2021 /Revised: 3 May 2021 / Accepted: 10 May 2021 / Published online: 27 May 2021

(C) Springer-Verlag GmbH Germany, part of Springer Nature 2021

\begin{abstract}
A fast PCR-assisted impedimetric biosensor was developed for the selective detection of the clbN gene from the polyketide synthase (pks) genomic island in real Escherichia coli samples. This genomic island is responsible for the production of colibactin, a harmful genotoxin that has been associated with colorectal cancer. The experimental protocol consisted of immobilizing the designated forward primer onto an Au electrode surface to create the sensing probe, followed by PCR temperature cycling in blank, positive, and negative DNA controls. Target DNA identification was possible by monitoring changes in the system's charge transfer resistance values $\left(\mathrm{R}_{\mathrm{ct}}\right)$ before and after PCR treatment through electrochemical impedance spectroscopy (EIS) analysis. Custom-made, flexible gold electrodes were fabricated using chemical etching optical lithography. A PCR cycle study determined the optimum conditions to be at 6 cycles providing fast results while maintaining a good sensitivity. EIS data for the DNA recognition process demonstrated the successful distinction between target interaction resulting in an increase in resistance to charge transfer $\left(\mathrm{R}_{\mathrm{ct}}\right)$ percentage change of $176 \%$ for the positive DNA control vs. $21 \%$ and $20 \%$ for the negative and non-DNA-containing controls, respectively. Results showed effective fabrication of a fast, PCR-based electrochemical biosensor for the detection of $p k s$ genomic island with a calculated limit of detection of $17 \mathrm{ng} / \mu \mathrm{L}$.
\end{abstract}

Keywords Electrochemical impedance spectroscopy $\cdot$ DNA biosensor $\cdot$ Polyketide synthase genomic island $\cdot$ Polymerase chain reaction $(\mathrm{PCR})$

\section{Introduction}

Colibactin is a DNA-damaging genotoxic secondary metabolite produced by the polyketide synthase multienzyme encoded by the pks genomic island [1]. Discovered in 2006

Published in the topical collection Analytical Chemistry for Infectious Disease Detection and Prevention with guest editors Chaoyong Yang and XiuJun (James) Li.

Carlos R. Cabrera

carlos.cabrera2@upr.edu

1 Department of Chemistry, Molecular Sciences Research Center, University of Puerto Rico, Río Piedras Campus, San Juan 00925-2537, Puerto Rico

2 Department of Biochemistry, Molecular Sciences Research Center, University of Puerto Rico, Medical Sciences Campus, San Juan 00936-5067, Puerto Rico

3 Future Industries Institute, University of South Australia, Mawson Lakes Campus, Mawson Lakes, Adelaide, South Australia 5095, Australia by Nougayrède [2]; the pks island is widely present in the human gut microbiota, harbored by certain strains of pathogenic and commensal Escherichia coli bacteria [3]. Although the chemical structure of the genotoxin has not been fully identified, its synthesis includes a complex assembly line composed of 19 genes denoted as clbA-clbS, where clbN and clbB are believed to be involved in its biosynthesis [4]. Many studies link colibactin production to colitis-associated colorectal cancer, therefore making it a molecule of interest in biomedical research [5-8].

The development of new platform designs and materials is an important factor to improve current in vivo and in-field biosensor applications [9]. Customarily, miniature electrode platforms are made up from metals, bioceramics, or inorganic semi-conductors because of their intrinsic high conductivity and high-definition processability; however, these suffer from low flexibility, bio-incompatibility, and bioinstability [10]. Recently, polymers have emerged as one of the most promising candidates for next-generation microelectrode arrays for both in vitro and in vivo applications [11]. Their chemical and 
physical properties offer advantages such as (1) relatively low density, (2) increased mechanical flexibility, and (3) lower costs that favors mass production [12].

Cyclic olefin copolymer (COC) is an amorphous thermoplastic composed of ethylene and norbornene polymers at varying ratios, utilized for small electronics due to its performance characteristics such as optical transparency, thermostability, and chemical resistance [13-15]. In the last few years, there has been an increase interest in the utilization of COC as biosensor substrate, specifically in microfluidics due to its micropatterning ease and biocompatibility [16-19].

Polymerase chain reaction, or PCR, is an extremely sensitive and precise enzymatic in vitro technique for the exponential amplification of DNA and RNA fragments from any kind of organism [20,21]. Its precision is defined by the selection of specific primers that will hybridize only with the nucleic acid molecule of interest, while its sensitivity has been proven to effectively detect and amplify as low as one copy of target DNA molecule [22, 23]. Since its invention in 1985, the PCR technique and PCR-based detection systems have been extensively studied for biomedical research [24-28], forensic studies [29, 30], environmental analysis [31-35], food industries $[36,37]$, and even at the international space station for extraterrestrial experimentation [38]. Although this method is more sensitive and less time consuming than its microorganismculture counterpart, it still requires multiple hours, materials, and equipment to be completed. An electrochemistry-based real-time polymerase chain reaction technique has been developed by Yeung et al. using a ferrocene redox marker to follow the surface process $[39,40]$. An electrochemical biosensor based on isothermal rolling circle amplification (RCA), nonPCR-based techniques, has been presented for rapid detection of SARS-CoV-2 [41]. The assay involves the hybridization of the RCA amplicons with redox-active label-functionalized probes for electrochemical detection.

In this work, a PCR-assisted electrochemical sensor for the detection of the clbN gene from the $p k s$ genomic island in real E. coli samples was developed. This biosensor utilizes the selectivity imparted by the PCR technique coupled with the sensitivity of the electrochemical impedance spectroscopy (EIS) measurements [42-44]. Combining the robustness of the COC substrate with the precision of the photolithography technique, where a robust biocompatible sensing platform with potential for future in vivo experimentation, was created. The experimental procedure consisted in the immobilization of the forward primer template or sensing probe onto a gold electrode, followed by PCR treatment with a positive, negative, or non-containing DNA control. Changes in the resistance to charge transfer $\left(\mathrm{R}_{\mathrm{ct}}\right)$ values were followed by EIS analysis [45]. Unlike other sensors, where lengthy PCR cycles and separation procedures need to be done, our PCR-assisted impedimetric biosensor was optimized to a two-step process consisting of only six (6) PCR cycles followed by direct impedimetric sensing.

\section{Experimental}

\section{Chemicals, materials, and equipment}

All reagents were obtained with high grades and used as received. The pks-containing IHE3034 was a kind donation from Dr. Eric Oswald at the University of Toulouse and the non-pks-containing DH10B Escherichia coli was purchased from Thermo Fisher. Both strains were cultivated in LB media and their genomic DNA was extracted by boiling for $10 \mathrm{~min}$ in nuclease-free water. Strain information is available in the Supplementary Information (ESM). Dilutions of several DNA concentrations were made from the stock solution with nuclease-free water and stored at $-20{ }^{\circ} \mathrm{C}$ until use. DNA concentration was measured using a UV NanoDrop. The oligonucleotide primers were purchased from Integrated DNA Technologies Inc., with the added amino terminal modifier in the forward primer to ease surface modification. The primer sequences are listed in Table 1. Upon arrival, the primers were diluted with nuclease-free nanopure water at $18.0 \mathrm{M} \Omega \mathrm{cm}$ resistivity, to reach a concentration of $10 \mu \mathrm{M}$, and stored at $-20{ }^{\circ} \mathrm{C}$ until use. Taq DNA polymerase kit and dNTPs were purchased from Thermo Fisher. PCR protocol was performed using a Bio-Rad T100TM Thermal Cycler with the following experimental conditions: a one-time 3-min initial denaturation period at $95^{\circ} \mathrm{C}$, followed by successive cycles of (1) denaturation at $94{ }^{\circ} \mathrm{C}$ for $1 \mathrm{~min},(2)$ annealing at $50.4{ }^{\circ} \mathrm{C}$ for $40 \mathrm{~s}$, and (3) extension for $1 \mathrm{~min}$ at $68{ }^{\circ} \mathrm{C}$, for a total PCR solution volume of $100 \mu \mathrm{L}$. Biologic VMP3 Potentiostat/ Galvanostat/EIS was utilized to perform all electrochemical analysis in a three-cell system, using a platinum mesh and silver/silver chloride as counter and reference electrode, respectively. Buffer solutions were prepared analytically, accounting for substance assay, and taken to desired $\mathrm{pH}$ with a Mettler Toledo $\mathrm{pH}$ meter.

\section{Electrode fabrication using optical lithography technique}

Flexible miniature electrodes were fabricated at the South Australian Node of the Australian National Fabrication

Table 1 DNA primer sequences utilized in the experiments

\begin{tabular}{ll}
\hline Name & Sequence $\left(5^{\prime}\right.$ to $\left.3^{\prime}\right)$ \\
\hline Forward primer & 5AmMC6/: TCGATATAGTCACGCCACCA \\
Reverse primer & GTGAAGTGGTCAGCCAAGTG \\
\hline
\end{tabular}


Facility (ANFF-SA) at University of South Australia. A bright-field, 7 by 7 -in. photomask was purchased from Front Range Photomask. COC plaques ( 6 by 6 in., 1 mm thickness) were bought from TOPAS $₫$ and used as received. Electrode fabrication process was performed as follows: (1) COC plaques were thoroughly washed with water, acetone, and isopropanol, and dried with $\mathrm{N}_{2}$ flux to remove any particles; (2) 100-nm layer of gold was plated using an HHV/Edwards TF500 sputter coater, followed by (3) AZ1518 photoresist coating at $2000 \mathrm{rpm}$ in a Karl Suss Delta 80 spin coater coupled with GYRSET®, and baked at $95{ }^{\circ} \mathrm{C}$ for $5 \mathrm{~min}$. Then, (4) the electrode design was patterned with a EVG 620 Mask Aligner, (5) developed, and (6) chemically etched in $\mathrm{KI} / \mathrm{I}_{2}$ for the removal of exposed gold layer followed by (7) acetone washing to remove the protecting photoresist, and lastly, (8) individual electrodes were cut with a Disco DAD 321 wafer dicer. Figure 1 shows a scheme of the finished electrode design and dimensions. Gold layer thickness was corroborated using an Optical Profilometer WYKO NT9100.

\section{Probe immobilization protocol}

Probe surface immobilization was performed as follows: (1) working electrode area was electrochemically clean by cycling in $0.5 \mathrm{M} \mathrm{H}_{2} \mathrm{SO}_{4}$ until a reproducible clean gold voltammogram was obtained, then (2) a compact layer of thioglycolic acid was created by adding a $15 \mu \mathrm{L}$ drop of $12 \mathrm{mM}$ TGA solution onto the working area for $2 \mathrm{~h}$, followed by (3) cross linker reaction formation for $1 \mathrm{~h}$ in $10 \mu \mathrm{L}$ of $20 \mathrm{mM} / 50 \mathrm{mM}$ EDC/Sulfo-NHS, respectively, and lastly, (4) reacted with forward DNA primer modified with an amino terminal group for $18 \mathrm{~h}$. Surface immobilization protocol was performed at $4{ }^{\circ} \mathrm{C}$ to minimize solution evaporation and DNA denaturalization. All solutions were maintained in ice while in use.

\section{Bio-electrochemical procedures}

Different PCR cycles have served as proof of concept for our PCR-assisted bio-electrochemical protocol design. Therefore, different PCR cycles at 2, 4, 6, 8, and 16 were studied to

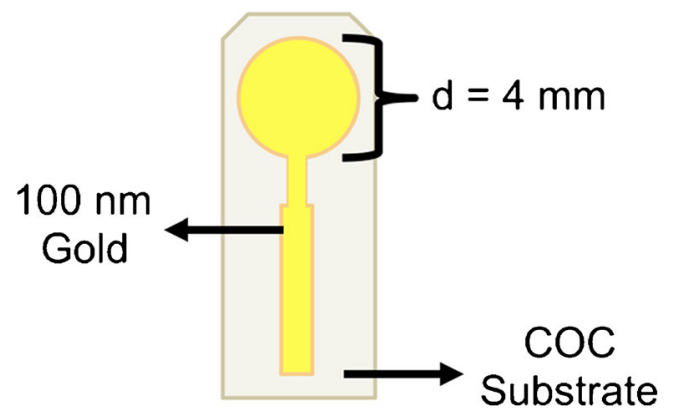

Fig. 1 Schematic representation of the custom miniature gold electrode and its dimensions balance the competing parameters of experimental analysis time and sensitivity. Also, target DNA concentrations ranging from 120 to $20 \mathrm{ng} / \mu \mathrm{L}$ were studied in order to calculate the limit of detection of our sensor. Figure 2 depicts the electrode surface modification and identification processes, where DNA primers are colored red, target strand is colored blue, and the amplified, new strand (amplicon) is colored green.

Impedimetric analysis was performed using a frequency range from $1 \mathrm{MHz}$ to $0.1 \mathrm{~Hz}$, with sinus amplitude of $20 \mathrm{mV}$ at an applied potential of $0.2 \mathrm{~V}$ vs. $\mathrm{Ag} / \mathrm{AgCl}$ in an iron buffer redox solution containing equimolar concentrations of $5 \mathrm{mM} \mathrm{Fe}\left[(\mathrm{CN})_{6}\right]^{3-/ 4-} / 0.1 \mathrm{M}$ PBS at $\mathrm{pH}$ 7.0. All experiments were performed in triplicates, utilizing a platinum mesh and silver-silver chloride as counter and reference electrode, respectively. Charge transfer resistance values $\left(\mathrm{R}_{\mathrm{ct}}\right)$ were determined by fitting the resulting Nyquist plot using the extended Randles equivalent circuit and compared as percentage change to correct for electrode-to-electrode working area variability utilizing Eq. 1.

$\left[\left(R_{c t \text { After }}-R_{c t \text { Before }}\right) / R_{c t \text { Before }}\right] \times 100$

where $\mathrm{Rct}_{\mathrm{Before}}$ and $\mathrm{Rct}_{\mathrm{After}}$ corresponds to the charge transfer resistance value before and after PCR treatment, respectively.

\section{Results and discussion}

\section{Miniature gold electrodes}

In order to effectively perform bio-electrochemical experiments, the creation of an electrode that met the following characteristics was needed: (1) electrochemically active, (2) resistance to high and low temperatures without sacrificing its integrity, (3) small size to fit in a $0.2-\mathrm{mL}$ PCR tube, (4) resistance to harsh chemical environments, (5) low production/retail costs, and (6) high reproducibility. Custom miniature gold electrodes were developed to comply with these necessities, following the fabrication protocol mentioned in the experimental section above. Surface roughness was characterized by scanning electron microscopy (SEM) images. ESM Fig. S1A shows the edge between the electrode and the substrate, accounting for good optical lithography performance. ESM Fig. S1 B-D illustrate the uniformity of the gold layer at different microscope magnifications. Energy dispersive spectroscopy (EDS) spectra in ESM Fig. S1 E show the atomic composition of the custom electrode accounting for a high percentage of gold as expected, while the X-ray photoelectron spectroscopy (XPS) spectra in ESM Fig. S1 F show the characteristic $\mathrm{Au}$ 4f 5/2 and 4f $7 / 2$ binding energy peaks, with an estimated separation of $3.7 \mathrm{eV}$, further proving electrode integrity. 


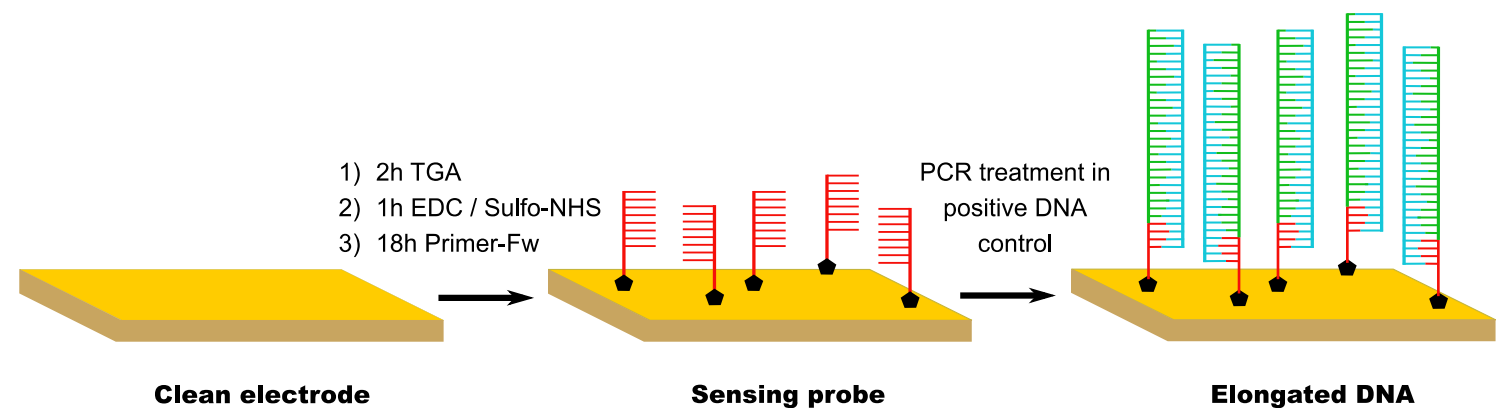

Fig. 2 Graphic scheme showing forward primer immobilization protocol and target DNA sensing mechanism, where DNA primers are colored red, and positive target DNA strand and amplicon are colored blue and green, respectively

Electrochemical characterization was also carried out to study the behavior of the miniature electrodes. A custom electrochemical cell cap was fabricated with polylactic acid (PLA) filament using an Ultimaker-3 3D printer to accommodate the silhouettes of each electrode and provide a constant distance between the working and counter electrodes to control the overall solution resistance. Figure 3 shows the finished electrochemical cell arrangement as viewed from the (A) side and (B) top. Figure 3C displays a miniature gold electrode besides a US penny for size comparison while Fig. 3D shows a representative clean gold cyclic voltammogram. Cleaning conditions were optimized to a voltage window of $0.2-1.6 \mathrm{~V}$ vs. $\mathrm{Ag} / \mathrm{AgCl}$ at $50 \mathrm{mV} / \mathrm{s}$ in $0.5 \mathrm{M} \mathrm{H}_{2} \mathrm{SO}_{4}$. Physical cleaning was limited to acetone and isopropanol rinsing followed by drying with a $\mathrm{N}_{2}$ flux. Electrochemical characterization showed only gold contribution, confirming the absence of impurities; also, low capacitance values at low voltages combined with well definition of the oxidation peaks further express the quality of the fabrication process.

\section{Sensing procedure characterization}

Indirect self-assembled monolayer method was used to immobilize the forward primer onto the Au electrode surface in order to reduce the non-specific adsorptions. The probe preparation and sensing process was followed through electrochemical impedance spectroscopy with PCR parameters being four cycles in $120 \mathrm{ng} / \mu \mathrm{L}$ of positive DNA control sample at a total volume of $100 \mu \mathrm{L}$. Figure 4 shows the respective Nyquist plots for bare gold electrode (black), after $2 \mathrm{~h}$ TGA immobilization (red), resulting sensing probe before PCR treatment (blue), and after effective DNA elongation due to recognition of target DNA (magenta). Inset shows a close-up of the semicircle region for the before and after PCR measurements. Initially, an increase in resistance is observed upon TGA immobilization, which has been attributed in the literature to the blockage of electron exchange between the iron and the electrode surface due to the formation of Au-thiol bonds [46]. On the other hand, a significant decrease in resistance is then observed for the primer-containing sensing probe. This behavior is characteristic of polyelectrolyte molecules such as aptamers, whose negatively charged phosphate backbone enables electron exchange [47]. However, upon DNA elongation due to the presence of positive control, the $R_{c t}$ value increases again. This occurs because of impedimetric hindrance caused by the very crowded elongated now-double helix DNA molecules modified onto the electrode surface. See Fig. 4 inset. The impedimetric behavior of our system demonstrates that effective surface modification is taking place, and that EIS can detect said changes through charge transfer resistance values.

\section{DNA detection analyses}

To optimize the sensor sensitivity, a PCR cycle analysis was performed. We first determined the best signal-to-time ratio in order to create a sensitive sensor that is also fast-acting in comparison with traditional full-cycled PCR analysis. For this, $2,4,6,8$, and 16 PCR cycles were studied. Figure 5 shows the respective charge transfer resistance percentage change averages before and after PCR treatment, and the $\Delta \mathrm{R}_{\mathrm{ct}} /$ time ratio in $\% / \mathrm{s}$. A rise in $\mathrm{R}_{\mathrm{ct}}$ value with increase cycle number is observed, as expected, due to the high concentration of PCR amplicons in the reaction mixture. However, this tendency does not follow a linear pattern, showing a slope reduction and, therefore, propensity to plateau at higher number of cycles. The blue scattered plot in Fig. 5 represents the $\Delta \mathrm{R}_{\mathrm{ct}}$ percentage change/PCR analysis time ratio. In other terms, the amount of signal "generated" over time of PCR analysis. Here, we observe a decreasing linear tendency with increasing number of cycles, meaning that the system loses efficiency over time. Due to that $2 \mathrm{PCR}$ cycles produce the lower $\mathrm{R}_{\mathrm{ct}}$ change, and 16 cycles take over $1 \mathrm{~h}$ to run, six cycles were chosen as optimum condition to balance experimental time with signal response.

To test the selectivity of our sensor, we studied the behavior when exposed to a non-DNA-containing and negative DNA control. Figure 6 shows the resulting bar chart for the selectivity study of our sensor at six PCR cycles. A distinctive increase in $R_{c t}$ percentage change is observed when exposed 
Fig. 3 A Side and $\mathbf{B}$ top view of the electrochemical cell arrangement. C Size comparison and $\mathbf{D}$ representative clean cyclic voltammogram for a miniature gold electrode. $\mathrm{CV}$ parameters: in $0.5 \mathrm{M} \mathrm{H}_{2} \mathrm{SO}_{4}$, from 0.2 to $1.6 \mathrm{~V}$ vs. $\mathrm{Ag} / \mathrm{AgCl}(3 \mathrm{M} \mathrm{KCl})$ at $50 \mathrm{mV} /$
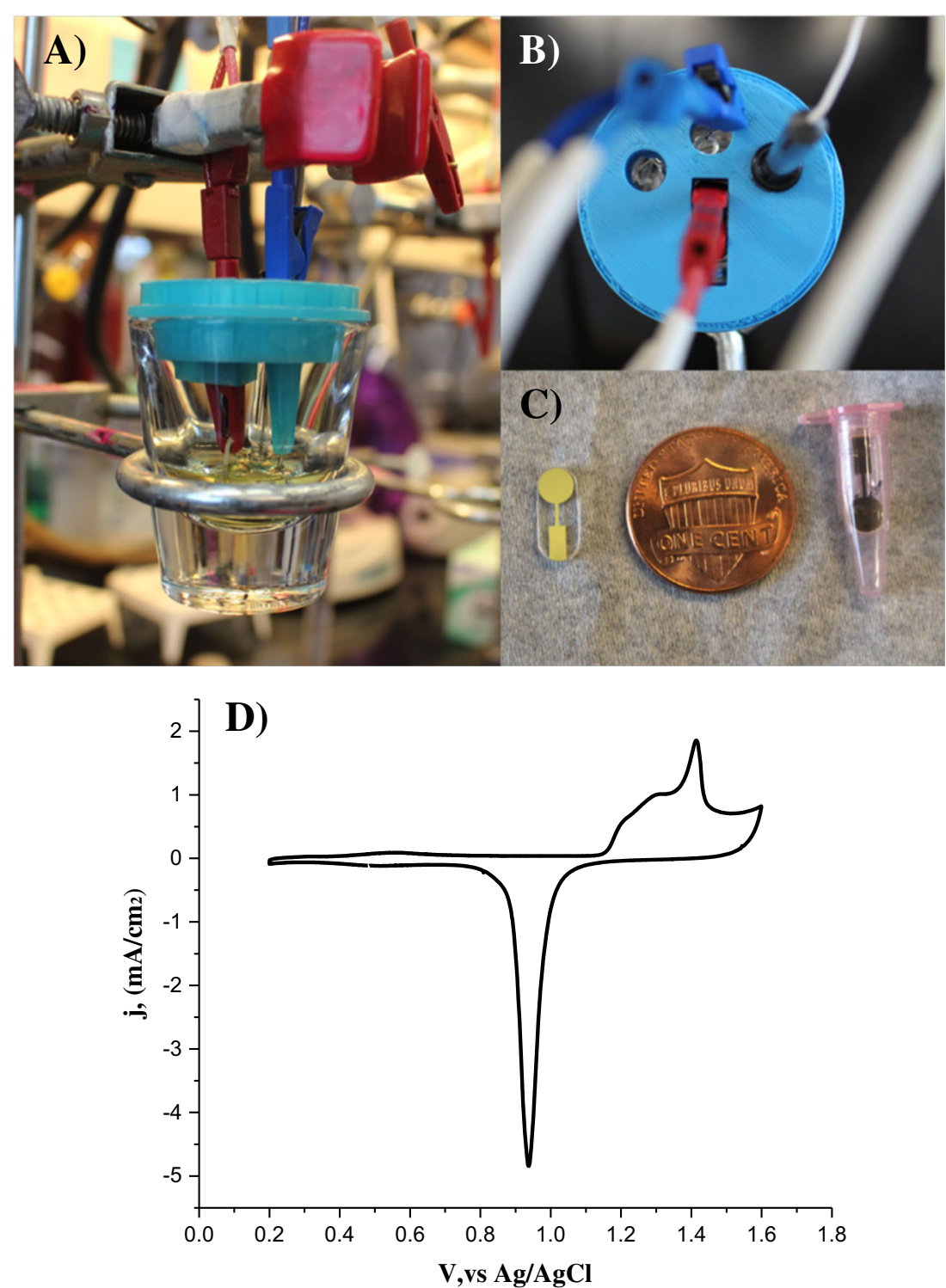

$\mathrm{DL}=F \cdot \mathrm{SD}_{b} / m$

to positive DNA control, proving effective target recognition. Both non-DNA-containing blank and negative control analysis resulted in a low $\mathrm{R}_{\mathrm{ct}}$ change around $20 \%$, as expected, because no elongation of the probe is occurring. Whatever change in $\mathrm{R}_{\mathrm{ct}}$ is observed can be attributed to matrix effects given the complexity of the PCR solution.

In order to optimize the biological parameters and determine the limit of detection of the system, we performed a positive control DNA calibration curve with target DNA concentration ranging from 20 to $120 \mathrm{ng} / \mu \mathrm{L}$. Figure 7 shows the resulting graphic.

A linear tendency with a slope value of 1.41 and a regression of 0.9897 is observed, with the lower distinguishable studied target DNA concentration being $20 \mathrm{ng} / \mu \mathrm{L}$ with a $27 \% \mathrm{R}_{\mathrm{ct}}$ percentage change value in comparison with the $21 \%$ obtained for the negative control. Limit of detection was calculated utilizing Eq. 2 [48] as follows: where DL is the detection limit, $F$ is a factor equivalent to 3 , $\mathrm{SD}_{\mathrm{b}}$ is the standard deviation of the blank, and $m$ is the slope of the regression line. The calculated biosensor detection limit is $17 \mathrm{ng} / \mu \mathrm{L}$.

\section{Biosensor comparison with literature}

To the best of our knowledge, this is the first sensor created for the detection of the polyketide synthase genomic island as well as the pioneer in utilizing a PCR DNA primer as probe. The majority of PCR-based electrochemical sensors in the literature utilize the immobilization of complementary amplicon strand as probe, following the hybridization process after amplification through current changes given by redox labels. 


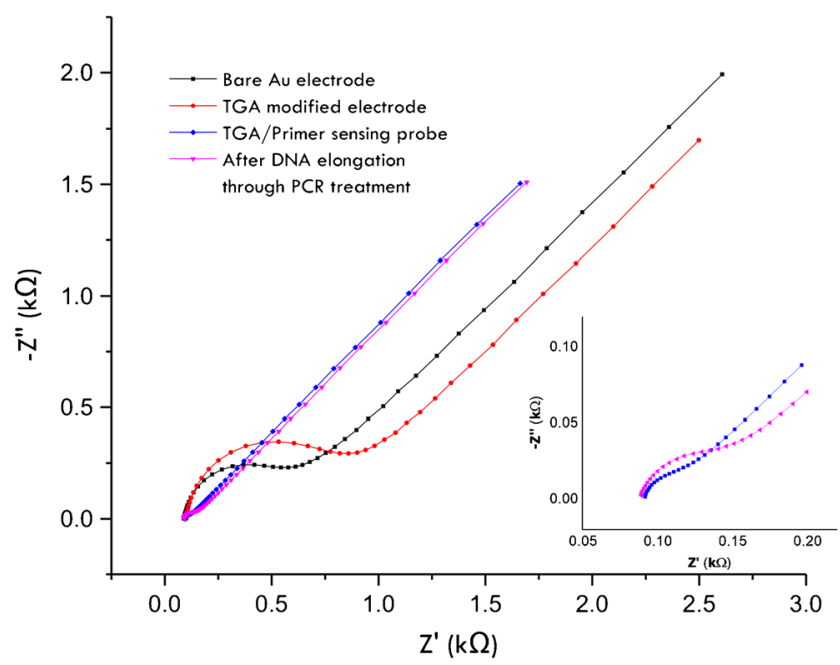

Fig. 4 Nyquist plots following the surface probe immobilization and target DNA recognition after PCR treatment: Bare Au electrode (black), TGA-modified Au electrode (orange), TGA/primer-modified Au electrode (blue), and after DNA elongation through PCR treatment (pink)

Moreover, most of them utilize reverse transcription PCR, or real-time PCR which are variables of the original PCR technique that allows for the utilization of RNA molecules and real-time quantification. While our developed bioelectrochemical protocol cannot be directly compared with the PCR-based sensors in the literature, recent works reported limit of detection down to 1 copy, making rtPCR technique worth exploring in the future [49].

\section{Conclusions}

Miniature gold electrodes were successfully fabricated and employed, with characterization showing no impurities and

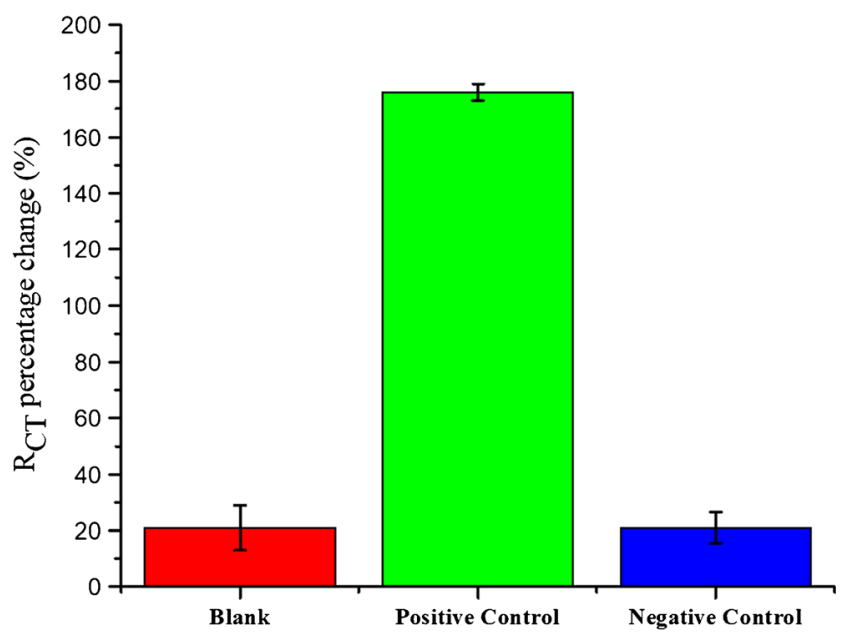

Fig. 6 Resistance to charge transfer $\left(\mathrm{R}_{\mathrm{ct}}\right)$ percentage change bar chart representing the selectivity of the sensor by exposure to non-containing blank (red), positive (green), and negative (blue) DNA controls at six (6) PCR cycles

high detailing. The utilization of a COC substrate provided electrode robustness in terms of quality of gold adhesion and ability to be utilized in a wide range of chemical and physical environments, such as high and low temperatures, acidic and organic solutions, and frequency and voltage sweeping. The biosensing mechanism was electrochemically characterized demonstrating effective surface modifications and detection protocols. Varying PCR cycles were studied against the analysis time to optimize the sensor sensitivity and signal-to-time ratio, being six cycles chosen as the better alternative. Selectivity experiments indicated a clear distinction between the positive DNA control and the negative DNA controls providing a $R_{c t}$ percentage change of $176 \%$ and $21 \%$, respectively. Target DNA concentration analysis at 6 PCR cycles demonstrated a linear tendency from 120 through $20 \mathrm{ng} / \mu \mathrm{L}$ with a
Fig. 5 Graphical scheme showing the resistance to charge transfer $\left(\mathrm{R}_{\mathrm{ct}}\right)$ percentage difference before and after PCR treatment (orange bar chart), and $\Delta \mathrm{R}_{\mathrm{ct}} /$ time ratio (blue scatter plot) at different PCR cycle numbers

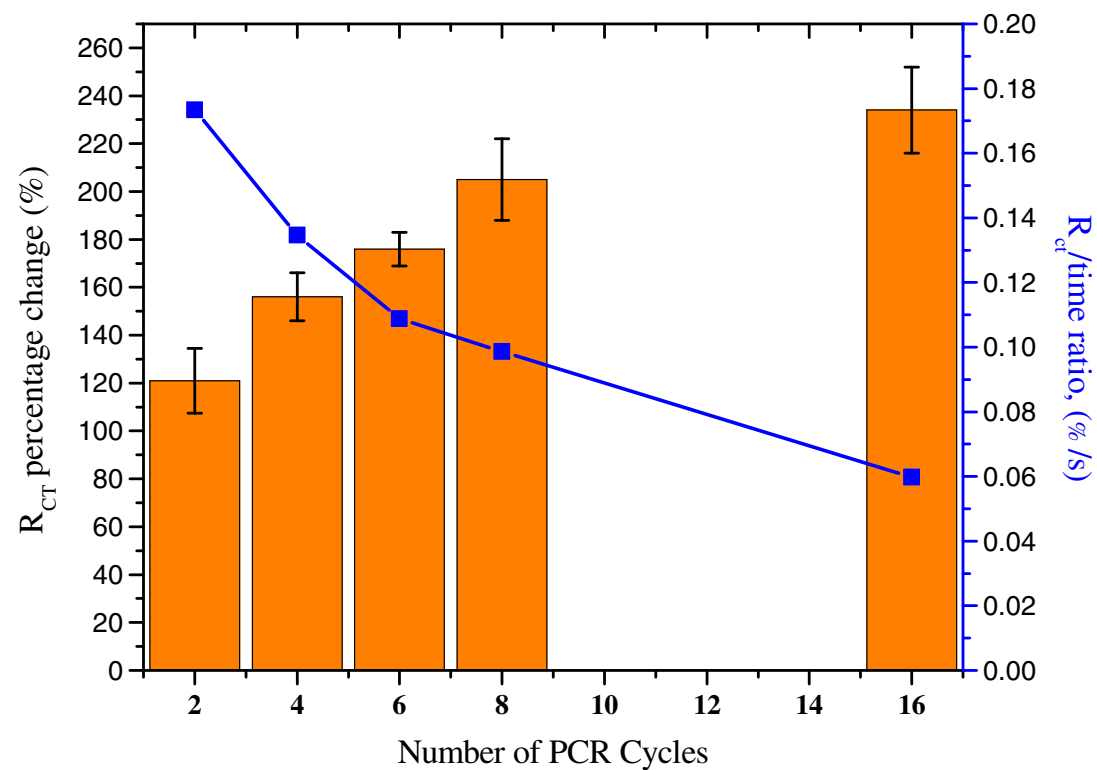




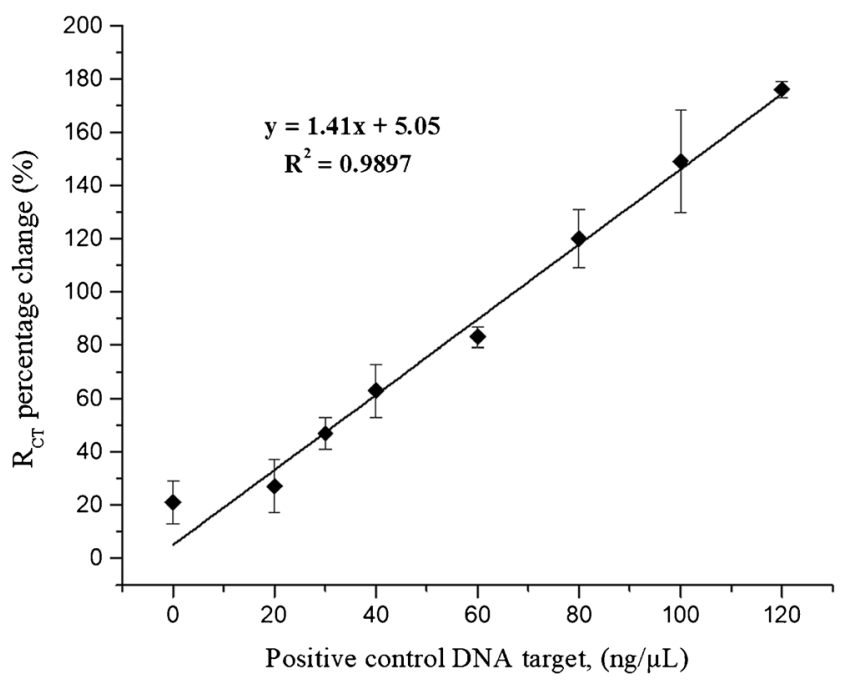

Fig. 7 pks-containing positive DNA control calibration curve, $\mathrm{R}_{\mathrm{ct}}$ percentage difference vs. positive control DNA target concentration, at six (6) PCR cycles

0.9897 linear regression and a calculated detection limit of $17 \mathrm{ng} / \mu \mathrm{L}$. In conclusion, results showed the effective detection of the colibactin-encoding $p k s$ genomic island in E. coli samples, using our fabricated biosensor platform and bioelectrochemical protocol. Interdigitated array microelectrodes can be studied as a prospective improvement to the sensor by employing a two-electrode system that serves as a lab-on-achip device, further simplifying the electrochemical process. Storage and stability studies must be carried out in order to fully characterize the system properties. Potential embodiments of this device could be used to detect the pks island and other toxin genes of bacterial origin, directly in clinical samples such as stool, saliva, or urine. Moreover, the designed protocol can be applied to the sensing of a variety of organisms by tailoring the DNA primers and PCR conditions including the possibility of in vivo applications due to the biocompatible nature of the sensing platform and procedures.

Supplementary Information The online version contains supplementary material available at https://doi.org/10.1007/s00216-021-03404-6.

Acknowledgements This work was done in part at the South Australian node of the Australian National Fabrication Facility, supported by Australia's National Collaborative Research Infrastructure Strategy. The authors would like to extend special thanks to Armando Peña-Duarte (UPR), for his contribution in the physical characterization procedures.

Funding Financial support by NSF-CREST Grant Number 1736093 , NIH-RISE Fellowship Grant No. 5R25GM061151, and Puerto Rico NASA Space Grant Consortium Grant No. NNX10AM80H are gratefully acknowledged. The Australian Academy of Science is acknowledged for supporting the University of Puerto Rico/University of South Australia collaboration.

\section{Declarations}

Conflict of interest The authors declare no competing interests.

\section{References}

1. Bossuet-Greif N, Dubois D, Petit C, Tronnet S, Martin P, Bonnet R, et al. Escherichia coli ClbS is a colibactin resistance protein. Mol Microbiol. 2016;99(5):897-908.

2. Nougayrède J-P, Homburg S, Taieb F, Boury M, Brzuszkiewicz E, Gottschalk G, et al. Escherichia coli induces DNA double-strand breaks in eukaryotic cells. Science. 2006;313(5788):848.

3. Balskus EP. Colibactin: understanding an elusive gut bacterial genotoxin. Nat Prod Rep. 2015;32(11):1534-40.

4. Faïs T, Delmas J, Barnich N, Bonnet R, Dalmasso G. Colibactin: more than a new bacterial toxin. Toxins. 2018;10(4):151.

5. Brotherton CA, Wilson M, Byrd G, Balskus EP. Isolation of a metabolite from the pks island provides insights into colibactin biosynthesis and activity. Org Lett. 2015;17(6):1545-8.

6. Arthur JC, Perez-Chanona E, Mühlbauer M, Tomkovich S, Uronis JM, Fan T-J, et al. Intestinal inflammation targets cancer-inducing activity of the microbiota. Science. 2012;338(6103):120.

7. Gómez-Moreno R, Robledo IE, Baerga-Ortiz A. Direct detection and quantification of bacterial genes associated with inflammation in DNA isolated from stool. Adv Microbiol. 2014;4(15):1065-75.

8. Morales-Lozada Y, Gómez-Moreno R, Báez-Bravo G, Robledo IE, Suazo-Dávila D, Cabrera CR, et al. The accumulation of colibactin intermediates does not affect the growth and morphology of $\mathrm{pks}^{+}$ Escherichia coli. bioRxiv. 2020;2020.04.17.047712.

9. Vigneshvar S, Sudhakumari CC, Senthilkumaran B, Prakash H. Recent advances in biosensor technology for potential applications - an overview. Front Bioeng Biotechnol. 2016;4:11. https://doi.org/ 10.3389/fbioe.2016.00011.

10. Blau A, Murr A, Wolff S, Sernagor E, Medini P, Iurilli G, et al. Flexible, all-polymer microelectrode arrays for the capture of cardiac and neuronal signals. Biomater. 2011;32(7):1778-86.

11. Sessolo M, Khodagholy D, Rivnay J, Maddalena F, Gleyzes M, Steidl E, et al. Easy-to-fabricate conducting polymer microelectrode arrays. Adv Mater. 2013;25(15):2135-9.

12. Qin Y, Howlader MMR, Deen MJ, Haddara YM, Selvaganapathy PR. Polymer integration for packaging of implantable sensors. Sensors Actuators B Chem. 2014;202:758-78.

13. Biron M. 4 - Detailed accounts of thermoplastic resins. In: Biron M, editor. Thermoplastics and thermoplastic composites. 2nd ed: William Andrew Publishing; 2013. p. 189-714.

14. Choi KY. New developments in polymer reaction engineering. In: Rhee H-K, Nam I-S, Park JM, editors. Studies in surface science and catalysis. 159: Elsevier; 2006. p. 109-14.

15. McKeen LW. 1 - Introduction to use of plastics in food packaging. In: Ebnesajjad S, editor. Plastic films in food packaging. Oxford: William Andrew Publishing; 2013. p. 1-15.

16. Hosseini S, Ibrahim F, Djordjevic I, Koole LH. Recent advances in surface functionalization techniques on polymethacrylate materials for optical biosensor applications. Analyst. 2014;139(12):2933-43.

17. Bruijns B, Veciana A, Tiggelaar R, Gardeniers H. Cyclic olefin copolymer microfluidic devices for forensic applications. Biosensors. 2019;9(3):85. https://doi.org/10.3390/bios9030085.

18. Prada J, Cordes C, Harms C, Lang W. Design and manufacturing of a disposable, cyclo-olefin copolymer, Microfluidic Device for a Biosensor. Sensors. 2019;19(5):1178. 
19. Morales-Cruz M, Solis-Marcano NE, Binder C, Priest C, Cabrera CR. Electrochemical Proteus vulgaris whole cell urea sensor in synthetic urine. CRBIOT. 2019;1:22-27. https://doi.org/10.1016/j. crbiot.2019.07.002.

20. Rahman M, Salah Uddin M, Sultana R, Moue A, Setu M. Polymerase chain reaction (PCR): a short review. 2013.

21. Takei F, Nakatani K. The chemistry of PCR primers: concept and application. Israel J Chem. 2013;53(6-7):401-16.

22. Garibyan L, Avashia N. Polymerase chain reaction. J Invest Dermatol. 2013;133(3):1-4.

23. Arya M, Shergill I, Williamson M, Gommersall L, Arya N, Patel RHH. Basic principles of real-time quantitative PCR2005. 209-19 p.

24. Cao L, Cui X, Hu J, Li Z, Choi JR, Yang Q, et al. Advances in digital polymerase chain reaction (dPCR) and its emerging biomedical applications. Biosens Bioelectron. 2017;90:459-74.

25. Pilotte N, Papaiakovou M, Grant JR, Bierwert LA, Llewellyn S, McCarthy JS, et al. Improved PCR-based detection of soil transmitted Helminth infections using a next-generation sequencing approach to assay design. PLoS Negl Trop Dis. 2016;10(3): e0004578.

26. Clem AL, Sims J, Telang S, Eaton JW, Chesney J. Virus detection and identification using random multiplex (RT)-PCR with 3 'locked random primers. Virol J. 2007;4(1):65.

27. Kradin R, Deshpande V, Iafrate AJ. 2 - General principles in the diagnosis of infection. In: Kradin RL, editor. Diagnostic pathology of infectious disease. 2nd ed: Elsevier; 2018. p. 3-15.

28. Remmers EF, Ombrello MJ, Siegel RM. 12 - Principles and techniques in molecular biology. In: Hochberg MC, Silman AJ, Smolen JS, Weinblatt ME, Weisman MH, editors. Rheumatology. 2nd ed. Philadelphia: Content Repository Only! 2015. p. 86-98.

29. Jung JY, Yoon HK, An S, Lee JW, Ahn E-R, Kim Y-J, et al. Rapid oral bacteria detection based on real-time PCR for the forensic identification of saliva. Sci Rep. 2018;8(1):10852.

30. Ottens R, Templeton J, Paradiso V, Taylor D, Abarno D, Linacre A. Application of direct PCR in forensic casework. Forensic Sci Int Genet Suppl Ser. 2013;4(1):e47-8.

31. Ridley AM, Allen VM, Sharma M, Harris JA, Newell DG. Realtime PCR approach for detection of environmental sources of Campylobacter strains colonizing broiler flocks. Appl Environ Microbiol. 2008;74(8):2492-504.

32. Kasturi KN, Drgon T. Real-time PCR method for detection of Salmonella spp. in environmental samples. Appl Environ Microbiol. 2017;83(14):e00644-17.

33. Fode-Vaughan KA, Wimpee CF, Remsen CC, Lynne Perille Collins M. Detection of bacteria in environmental samples by direct PCR without DNA extraction. BioTechniques. 2001;31(3):598607.

34. Loge FJ, Thompson DE, Call DR. PCR detection of specific pathogens in water: a risk-based analysis. Environ Sci Technol. 2002;36(12):2754-9.

35. Alvarez AJ, Buttner MP, Stetzenbach LD. PCR for bioaerosol monitoring: sensitivity and environmental interference. Appl Environ Microbiol. 1995;61(10):3639.
36. Josefsen MH, Cook N, D'Agostino M, Hansen F, Wagner M, Demnerova K, et al. Validation of a PCR-based method for detection of food-borne thermotolerant campylobacters in a multicenter collaborative trial. Appl Environ Microbiol. 2004;70(7):4379-83.

37. Malorny B, Paccassoni E, Fach P, Bunge C, Martin A, Helmuth R. Diagnostic real-time PCR for detection of Salmonella in food. Appl Environ Microbiol. 2004;70(12):7046.

38. Boguraev A-S, Christensen HC, Bonneau AR, Pezza JA, Nichols NM, Giraldez AJ, et al. Successful amplification of DNA aboard the International Space Station. NPJ Microgravity. 2017;3(1):26. https://doi.org/10.1038/s41526-017-0033-9.

39. Yeung SSW, Lee TMH, Hsing IM. Electrochemical real-time polymerase chain reaction. J Am Chem Soc. 2006;128(41):13374-5.

40. Yeung SSW, Lee TMH, Hsing IM. Electrochemistry-based realtime PCR on a microchip. Anal Chem. 2008;80(2):363-8.

41. Chaibun T, Puenpa J, Ngamdee T, Boonapatcharoen N, Athamanolap P, O'Mullane AP, et al. Rapid electrochemical detection of coronavirus SARS-CoV-2. Nat Commun. 2021;12(1): 802. https://doi.org/10.1038/s41467-021-21121-7.

42. Leva-Bueno J, Peyman SA, Millner PA. A review on impedimetric immunosensors for pathogen and biomarker detection. Med Microbiol Immunol. 2020;209(3):343-62.

43. Soraya GV, Abeyrathne CD, Buffet C, Huynh DH, Uddin SM, Chan J, et al. Ultrasensitive and label-free biosensor for the detection of Plasmodium falciparum histidine-rich protein II in saliva. Sci Rep. 2019;9(1):17495.

44. Purohit B, Vernekar PR, Shetti NP, Chandra P. Biosensor nanoengineering: design, operation, and implementation for biomolecular analysis. Sens Int. 2020;1:100040.

45. Díaz-Cartagena DC, Hernández-Cancel G, Bracho-Rincón DP, González-Feliciano JA, Cunci L, González CI, et al. Label-free telomerase activity detection via electrochemical impedance spectroscopy. ACS Omega. 2019;4(16):16724-32.

46. An Y. Sensitive electrochemical cytosensor based on biocompatibleAu@BSA conductive architecture and lectin-modified nanoprobe. J Electrochem Soc. 2016;163(6):B242-7.

47. Esfandyarpour R, Javanmard M, Koochak Z, Esfandyarpour H, Harris JS, Davis RW. Label-free electronic probing of nucleic acids and proteins at the nanoscale using the nanoneedle biosensor. Biomicrofluidics. 2013;7(4):44114. https://doi.org/10.1063/1. 4817771.

48. Shrivastava A, Gupta V. Methods for the determination of limit of detection and limit of quantitation of the analytical methods. Chron Young Sci. 2011;2(1):21-5.

49. Hamdy ME, Del Carlo M, Hussein HA, Salah TA, El-Deeb AH, Emara MM, et al. Development of gold nanoparticles biosensor for ultrasensitive diagnosis of foot and mouth disease virus. J Nanobiotechnol. 2018;16(1):48. https://doi.org/10.1186/s12951018-0374-x.

Publisher's note Springer Nature remains neutral with regard to jurisdictional claims in published maps and institutional affiliations. 